Hubungan Lama Kerja dan Status Gizi dengan Kelelahan Kerja pada Pengrajin Emas

\title{
Relationship of Length of Work and Nutritional Status with Work Fatigue at Gold Craftsmen
}

\author{
Nur Juliana ${ }^{1}$, Firnasrudin Rahim ${ }^{2}$, Wa Ode Megasari ${ }^{3}$, Hamzah B ${ }^{4}$ \\ ${ }^{1,2}$ Program Studi Promosi Kesehatan, Politeknik Karya Persada Muna \\ ${ }^{3}$ Program Studi Administrasi Rumah Sakit, Politeknik Karya Persada Muna \\ ${ }^{4}$ Program Studi Kesehatan Masyarakat, Institut Kesehatan dan Teknologi Graha Medika \\ (juli.faidah@gmail.com, 082344380390)
}

\begin{abstract}
ABSTRAK
Permasalahan yang sering muncul pada pekerja di sektor industri termasuk industri rumah tangga seperti pengrajin emas adalah kelelahan kerja. Data menunjukkan prevalensi kelelahan kerja pada pekerja mencapai dari 10\% hingga 40\%. Pengrajin emas yang masih bekerja secara manual, lama bekerja lebih dari 8 jam/hari dan postur tubuh yang tidak ideal sehingga berisiko mengalami kelelahan kerja. Penelitan ini bertujuan untuk mengetahui hubungan antara lama kerja dan status gizi dengan kelelahan kerja pada pengrajin emas di Kelurahan Malimongan Kecamatan Wajo Kota Makassar. Jenis penelitian observasional analitik menggunakan pendekatan cross sectional study, melibatkan 30 orang pengrajin emas sebagai responden yang diambil secara simple random sampling. Pengumpulan data menggunakan kuisioner, timbangan badan dan stature meter yang selanjutnya dianalisis menggunakan non parametrik dengan uji Kruskal Wallis. Hasil penelitian menunjukkan bahwa lama kerja $\geq 8$ jam/hari sebanyak $44,3 \%$, status gizi normal sebanyak $70 \%$ dan kelelahan kerja sedang sebanyak $60 \%$. Analisis statistik menunjukkan ada hubungan antara lama kerja dengan kelelahan kerja pada pengrajin emas $(p$-value $=0,016)$ sedangkan status gizi dengan kelelahan kerja didapatkan ( $p$-value $=0,311)$. Sebagai kesimpulan diketahui bahwa ada hubungan antara lama kerja dengan kelelahan kerja, dan tidak ada hubungan antara status gizi dengan kelelahan kerja pada pengrajin emas.
\end{abstract}

Kata Kunci: Kelelahan kerja, lama kerja, status gizi, pengrajin emas

\section{ABSTRACT}

The problem that often arises for workers in the industrial sector, including household industries such as gold craftsmen, is work fatigue. Data shows the prevalence of work fatigue in workers reaches from $10 \%$ to $40 \%$. Gold craftsmen who are still working manually, working longer than 8 hours/day and having a body posture that is not ideal so they are at risk of experiencing work fatigue. This study aims to determine the relationship between length of work and nutritional status with work fatigue on gold craftsmen in Malimongan Village, Wajo District, Makassar City. This type of analytic observational research uses a cross sectional study approach, involving 30 gold craftsmen as respondents who were taken by simple random sampling. Collecting data using questionnaires, body scales and stature meters which are then analyzed using non-parametric methods with the Kruskal Wallis test. The results showed that the length of work 8 hours/day was 44,3\%, normal nutritional status was $70 \%$ and work fatigue was $60 \%$. Statistical analysis showed that there was a relationship between length of work and work fatigue for gold craftsmen $(p$-value $=0,016)$ while nutritional status and work fatigue were obtained ( $p$-value=0,311). In conclusion, it is known that there is a relationship between length of work and work fatigue, and there is no relationship between nutritional status and work fatigue in gold craftsmen.

Keywords: Work fatigue, length of work, nutritional status, gold craftsmen 


\section{PENDAHULUAN}

Salah satu permasalahan kesehatan dan keselamatan yang dialami para pekerja adalah kelelahan akibat kerja. Hal ini akan berisiko terhadap kecelakaan saat bekerja. Data dari International Labour Organitation (ILO) menunjukkan setiap tahun ada dua juta pekerja yang meninggal dunia akibat kelelahan kerja. Penelitian sebelumnya menjelaskan dari 58.115 sampel terdapat $32,8 \%$ diantaranya mengalami kelelahan kerja, pekerja yang mengalami kelelahan kerja akan berisiko mengalami kecelakaan kerja sehingga berdampak pada produktivitas kerja. ${ }^{1}$

Pertumbuhan tenaga kerja di Indonesia mencapai $4 \%$ pertahun di sektor industri. Dari tahun 2009-2016 setiap 1\% pertumbuhan di sektor industri pertumbuhan tenaga kerja mencapai $0,79 \%$. Peningkatan di sektor industri dan tenaga kerja akan meningkatkan risiko masalah kesehatan dan keselamatan pada pekerja. Masalah yang sering ditemukan pada tenaga kerja adalah kelelahan kerja. Tercatat prevalensi kelelahan kerja bervariasi dari $10 \%$ hingga $40 \% .^{2}$

Salah satu sektor industri yang tumbuh cukup pesat di Indonesia adalah produksi emas. Kota Makassar menjadi salah satu sentra perdagangan perhiasan emas di Indonesia dari produksi emas moderen maupun produksi skala rumah tangga. Perhiasan emas ini dikerjakan oleh pengrajin emas, pengrajin emas ini banyak tersebar di beberapa tempat di Kota Makassar salah satunya di Kelurahan Malimongan Kecamatan Wajo.

Permasalahan yang ada pada skala industri rumah tangga (home industry), karena pekerjaan yang dilakukan masih manual, aktivitas kegiatan dari pekerjaan dengan postur tubuh atau posisi tubuh tidak normal menyebabkan kelelahan dan ketidaknyamanan. Jika pekerja sudah merasa lelah dan dipaksa untuk bekerja, hal tersebut dapat berefek terhadap kelelahan yang bertambah dan kelelahan yang muncul dapat mengganggu kelancaran pekerjaan dan berdampak buruk pada pekerja tersebut. ${ }^{3}$

Pembuatan perhiasan emas terdiri dari pemilihan bahan baku, peleburan, pemurnian menggunakan bahan kimia berbahan nitrat, merkuri, dan lain-lain, selanjutnya proses pengelasan, pelapisan bahan, dan memoles logam menjadi emas. Apabila dikerjakan terus-menurus dan jangka waktu lama tentunya akan berdampak pada kesehatan tubuh dan kelelahan kerja.

Kelelahan yang dialami pekerja berbeda tergantung masing-masing individu. Kelelahan yang dialami akan berakibat pada hilangnya efisiensi dan penurunan kinerja dan ketahanan tubuh, selain itu menurunkan kinerja serta menambah tingkat kesalahan kerja. ${ }^{4}$ Ciri-ciri kelelahan kerja umumnya dirasakan pekerja adalah rasa mengantuk, kepala terasa pusing, konsentrasi terganggu, otot terasa kaku dan susah bergerak, tidak mampu berdiri dalam jangka waktu lama. ${ }^{5}$

Berdasarkan hasil penelitian NSC bahwa pekerja yang beroperasi selama 24 jam menunjukkan tingkat kelelahan $13 \%$ serta mengalami cedera di tempat kerja yang dikaitkan dengan kelelahan. Selain itu, lebih dari $80 \%$ dari semua pekerja terpapar pada risiko kelelahan. ${ }^{6}$ Salah satu pekerjaan yang prosesnya melibatkan 
aktivitas yang berulang dan postur kerja posisi membungkuk ketika duduk adalah para pengrajin emas.

Kelelahan kerja sangat berkaitan dengan sifat pekerjaan yang tidak bervariasi, lama/durasi kerja, kebutuhan akan kesehatan mental dan fisik yang tinggi, pencahayaan tempat kerja, kebisingan serta lingkungan kerja lainnya yang tidak kondusif, ketegangan otot, rasa kesakitan, status gizi dan shift kerja. Selain itu, dibutuhkan waktu istirahat dan waktu bekerja yang proporsional sehingga dapat menurunkan tingkat kelelahan kerja. Durasi dan tepatnya waktu istirahat sangat dibutuhkan dalam menekan terjadinya kelelahan kerja pada pekerja. $^{7}$

Gizi pada pekerja merupakan hal penting yang harus diperhatikan oleh pekerja selama bekerja. Status gizi yang baik dapat menurunkan kelelahan dan meningkatkan kapasitas kerja. Gizi kerja merupakan zat-zat gizi yang diperlukan pekerja untuk memenuhi kebutuhan dalam bekerja yang sesuai dengan jenis pekerjaan yang dilakukan. ${ }^{8}$ Hasil penelitian yang dilakukan di PT. Sinar Pure Foods Internasional Bitung dengan jumlah sampel 75 orang pekerja dan di PT. Multi Aneka Pangan Nusantara dengan jumlah sampel sebanyak 33 pekerja menemukan ada hubungan status gizi dengan kelelahan kerja yang dialami pekerja. $^{9} 10$

Berdasarkan survei awal di Kelurahan Malimongan, hampir setiap rumah menekuni sebagai pengrajin emas, dikarenakan turuntemurun yang diwariskan dari generasi ke generasi. Proses pembuatan emas masih dilakukan secara tradisional dengan bantuan keluarga yang ada, sehingga secara tidak langsung anak-anak dan para pengrajin memiliki kemampuan untuk memproses emas menjadi suatu perhiasan. Selain itu, untuk keluhan kesehatan berdasarkan observasi bahwa pengrajin emas rata-rata mengeluhkan sakit otot, lelah di seluruh badan, sakit kepala dan sakit area bahu karena lamanya masa kerja dalam sehari-hari. Maka tujuan penelitian ini adalah untuk mengetahui hubungan lama kerja dan status gizi dengan kelelahan kerja pada pengrajin emas di Kelurahan Malimongan Kecamatan Wajo Kota Makassar.

\section{BAHAN DAN METODE}

Jenis penelitian yang digunakan adalah kuantitatif dengan desain observasional analitik. Penelitian ini dilaksanakan di rumah industri pengrajin emas di Kelurahan Malimongan Kota Makassar dengan rancangan cross sectional study, yang menjadi populasi pada penelitian ini semua pengrajin emas di Kelurahan Malimongan sebanyak 44 orang. Jumlah sampel penelitian didapatkan dengan menggunakan rumus Slovin sehingga sampel pada penelitian ini sebanyak 30 pengrajin emas, kemudian teknik sampel simple random sampling sehingga keseluruhan anggota populasi berkesempatan terpilih menjadi sampel dalam penelitian. ${ }^{11}$

Data dikumpulkan menggunakan kuesioner untuk mengetahui lama kerja, pengukuran berat badan menggunakan alat timbangan badan (satuan $\mathrm{kg}$ ) dan untuk tinggi badan menggunakan alat stature meter (satuan $\mathrm{cm}$ ) untuk mengetahui status gizi. Sedangkan pengukuran kelelahan kerja menggunakan kuisioner International Fatigue 
Research Committee (IRFC) yang berhubungan dengan gejala-gejala yang menunjukkan terjadinya kelelahan akibat kerja. ${ }^{5}$ Analisis data dilakukan secara univariat dan bivariat dengan uji Kruskal Wallis. Uji normalitas dilakukan sebelum dilakukan analisis bivariat. Pada penelitian ini dilakukan uji normalitas data, dengan syarat asymp sig $>0,05$ (distribusi normal) dan asymp sig $<0,05$ (distribusi tidak normal). ${ }^{12}$

\section{HASIL}

Hasil penelitian Tabel 1 menunjukkan bahwa bahwa karakteristik responden adalah semua lakilaki 30 orang (100\%). Berdasarkan kelompok umur pada pengrajin emas yang terbanyak di usia 36-45 tahun sebanyak 13 orang (43,3\%), usia 2635 tahun sebanyak 10 orang (33,3\%), usia 46-55 tahun sebanyak 5 orang $(16,7 \%)$ dan usia paling sedikit 55-65 tahun sebanyak 2 orang (6,7\%). Berdasarkan tingkat pendidikan pada pengrajin emas adalah SMP sebanyak 14 orang $(46,7 \%)$, SD sebanyak 10 orang $(33,3 \%)$, SMA sebanyak 5 orang $(16,7 \%)$, tidak sekolah 1 orang $(3,30 \%)$.

Hasil penelitian Tabel 2 menunjukkan bahwa dari 30 responden bahwa lama kerja dalam sehari pengrajin emas lebih banyak sama dengan 8 jam/hari kerja sebanyak 28 orang $(93,3 \%)$ dan sisanya $<8$ jam/hari sebanyak 2 orang $(6,7 \%)$. Sedangkan rata-rata $1,93 \mathrm{jam} / \mathrm{hari}$ dan standar deviasi $0,254 \mathrm{jam} /$ hari. Pada variabel status gizi dari 30 responden bahwa status gizi pengrajin emas terbanyak adalah normal 21 orang (70,0\%), dan paling sedikit adalah kurus 3 orang (10,0\%). Sedangkan rata-rata status gizi 2,10 dan standar deviasi 0,548. Pada variabel kelelahan kerja dari
30 responden bahwa kelelahan kerja pengrajin emas terbanyak adalah kategori sedang 18 orang (60\%), dan yang paling sedikit adalah rendah dan tinggi masing-masing 6 orang (20\%). Sedangkan rata-rata kelelahan kerja 2,00 dan standar deviasi 0,643 .

\section{Tabel 1. Distribusi Frekuensi Berdasarkan Karakteristik Responden di Kelurahan Malimongan}

\begin{tabular}{crr}
\hline $\begin{array}{c}\text { Karakteristik } \\
\text { Responden }\end{array}$ & $\mathbf{n}=\mathbf{( 3 0 )}$ & \multicolumn{1}{c}{$\%$} \\
\hline Jenis Kelamin & 30 & 100 \\
Laki-laki & 0 & 0 \\
Perempuan & & \\
Kelompok Umur & 10 & 33,3 \\
26-35 tahun & 13 & 43,3 \\
36-45 tahun & 5 & 16,7 \\
46-55 tahun & 2 & 6,7 \\
55-65 tahun & & \\
Tingkat Pendidikan & 1 & 3,30 \\
Tidak Sekolah & 10 & 33,3 \\
SD & 14 & 46,7 \\
SMP & 5 & 16,7 \\
SMA & 0 & 0 \\
PT & &
\end{tabular}

Sumber: Data Primer, 2018

Tabel 2. Distribusi Frekuensi Berdasarkan Lama Kerja, Status Gizi, dan Kelelahan Kerja Pengrajin Emas di Kelurahan Malimongan

\begin{tabular}{crrr}
\hline $\begin{array}{c}\text { Variabel } \\
\text { Penelitian }\end{array}$ & $\mathbf{n}=\mathbf{( 3 0 )}$ & $\%$ & $\begin{array}{c}\mathbf{x} \pm \\
\text { SD }\end{array}$ \\
\hline Lama Kerja & & & \\
$<$ < jam & 2 & 55,7 & $1,93 \pm$ \\
$\geq 8$ jam & 28 & 44,3 & 0,254 \\
Status Gizi & & & \\
Kurus & 3 & 10,0 & $2,10 \pm$ \\
Normal & 21 & 70,0 & 0,548 \\
Gemuk & 6 & 20,0 & \\
Kelelahan Kerja & & & \\
Rendah & 6 & 20,0 & $2,00 \pm$ \\
Sedang & 18 & 60,0 & 0,643 \\
Tinggi & 6 & 20,0 & \\
\hline
\end{tabular}

Sumber: Data Primer, 2018

Hasil uji normalitas pada Tabel 3 didapatkan nilai masing-masing variabel 0,000 lebih kecil daripada 0,05 artinya data tersebut data tidak 
terdistribusi normal, sehingga menggunakan analisis non parametrik. Hasil penelitian hubungan antara lama kerja dan status gizi dengan kelelahan kerja pada pengrajin emas di Kelurahan Malimongan berdasarkan pada Tabel 4.

Tabel 3. Hasil Uji Normalitas Data

\begin{tabular}{|c|c|c|c|c|c|}
\hline \multirow{2}{*}{\multicolumn{2}{|c|}{$\begin{array}{l}\text { Variabel } \\
\text { Penelitian }\end{array}$}} & \multicolumn{4}{|c|}{ Shaphiro-wilk } \\
\hline & & \multicolumn{2}{|c|}{ Statistik } & df & sig \\
\hline \multicolumn{2}{|l|}{ Lama Kerja } & \multicolumn{2}{|c|}{0,275} & 30 & 0,000 \\
\hline \multicolumn{2}{|l|}{ Status Gizi } & \multicolumn{2}{|c|}{0,271} & 30 & 0,000 \\
\hline \multicolumn{2}{|c|}{ Kelelahan Kerja } & \multicolumn{2}{|c|}{0,787} & 30 & 0,000 \\
\hline \multicolumn{6}{|c|}{ Sumber: Data Primer, 2018} \\
\hline \multicolumn{6}{|c|}{$\begin{array}{l}\text { Tabel 4. Analisis Hubungan Lama Kerja dan } \\
\text { Status Gizi terhadap Kelelahan Kerja } \\
\text { Pengrajin Emas di Kelurahan Malimongan }\end{array}$} \\
\hline $\begin{array}{c}\text { Variabel } \\
\text { Penelitian } \\
\end{array}$ & \multicolumn{2}{|c|}{ Kelelahan } & \multicolumn{2}{|c|}{$\begin{array}{l}\text { Mean } \\
\text { Rank }\end{array}$} & p value \\
\hline \multirow{3}{*}{$\begin{array}{l}\text { Lama } \\
\text { Kerja }\end{array}$} & \multicolumn{2}{|c|}{ Rendah } & \multicolumn{2}{|c|}{11,50} & \\
\hline & \multicolumn{2}{|c|}{ Sedang } & \multicolumn{2}{|c|}{16,50} & 0,016 \\
\hline & \multicolumn{2}{|c|}{ Tinggi } & \multicolumn{2}{|c|}{16,50} & \\
\hline \multirow{3}{*}{$\begin{array}{c}\text { Status } \\
\text { Gizi }\end{array}$} & \multicolumn{2}{|c|}{ Rendah } & \multicolumn{2}{|c|}{18,50} & \\
\hline & \multicolumn{2}{|c|}{ Sedang } & \multicolumn{2}{|c|}{15,58} & 0,311 \\
\hline & \multicolumn{2}{|c|}{ Tinggi } & \multicolumn{2}{|c|}{12,25} & \\
\hline
\end{tabular}

Sumber: Data Primer, 2018

Hasil penelitian Tabel 4 menunjukkan bahwa antara variabel tes (lama kerja) dengan grouping variabel (kelelahan kerja) sekilas terdapat perbedaan rata-rata, hanya saja pada kelelahan kerja intensitas tinggi rata-rata sama yaitu 16,50 sedangkan rata-rata kelelahan kerja dengan intensitas rendah adalah 11,50. Hasil analisis bivariat hubungan lama kerja dengan kelelahan kerja pada pengrajin emas diperoleh $p$ value $=0,016$ dimana $p$-value $<0,05$ sehingga Ho ditolak artinya ada hubungan lama kerja dengan kelelahan kerja.

Pada variabel status gizi didapatkan hasil bahwa antara variabel tes (status gizi) dengan grouping variabel (kelelahan kerja) terdapat perbedaan rata-rata kelelahan kerja intensitas rendah 18,50; kelelahan kerja intensitas sedang 15,58 dan kelelahan kerja intensitas tinggi 12,25. Hasil analisis bivariat hubungan status gizi dengan kelelahan kerja diperoleh $p$-value $=0,311$ dimana $p$ value > 0,05 maka Ho ditolak artinya tidak ada hubungan antara status gizi dengan kelelahan kerja.

\section{PEMBAHASAN}

Berdasarkan hasil penelitian yang menunjukkan karakteristik responden dari jenis kelamin, umur dan tingkat pendidikan, bahwa ratarata yang berkerja sebagai pengrajin emas adalah laki-laki dengan sampel 30 orang (100\%). Karakteristik responden berdasarkan umur 36-45 tahun sebanyak 13 orang $(43,3 \%)$, dimana kondisi umur berpengaruh dengan kekuatan otot dan fisik pengrajin emas. Sedangkan tingkat pendidikan terbanyak adalah SMP sebanyak 14 orang $(46,7 \%)$, karena pekerja lebih peduli dalam bekerja sebagai mata pencaharian guna memenuhi kebutuhan hidup.

Lama kerja merupakan waktu kerja dalam sehari yang digunakan oleh pengrajin emas di Kelurahan Malimongan dalam bekerja rata-rata antara 7 jam/hari dengan kategori $<8$ jam/hari dengan persentase $6,7 \%$, bahkan ada yang sampai $10 \mathrm{jam} / \mathrm{hari}$ kategori sama dengan atau $>8 \mathrm{jam} / \mathrm{hari}$ dengan persentase 93,3\%, karena jam kerja tiap pengrajin emas berbeda-beda. Selain itu, disebabkan oleh banyaknya pesanan atau permintaan perhiasan emas oleh toko dan konsumen sehingga pengrajin emas memiliki intensitas waktu jam kerja yang lama bahkan 
bekerja sampai malam hari. Sedangkan rata-rata dan standar deviasi masing-masing adalah 1,93 \pm 0,254 .

Hal yang mempengaruhi produktivitas kerja adalah lamanya waktu kerja, orang yang bekerja lebih dari 8 jam/hari akan mengalami kelelahan sehingga dapat mempengaruhi konsentrasi dalam kerja, waktu kerja seseorang dapat ditentukan oleh efisiensi dan produktivitasnya. Penelitian yang telah dilakukan sebelumnya menyatakan bahwa sebagian besar pekerja tukang emas bekerja dengan jam kerja 7-8 jam per hari (48\%), 8-9 jam per hari membantu untuk mendapatkan penghasilan yang tinggi dan bahkan bekerja di malam hari. Kadang-kadang jika acara meriah atau upacara sosial maka permintaan untuk perhiasan emas tinggi, pekerja bahkan bekerja selama 12-14 jam sehari. ${ }^{13}$

Hasil penelitian yang dilakukan pada dikomunitas Manguni Rider Online Sario yang membawahi pengendara ojek online dengan jumlah sampel sebanyak 40 orang, menemukan bahwa ada hubungan antara lama kerja dengan kelelahan kerja responden dengan nilai $p$ value $=0,023 .{ }^{14}$ Penelitian lain yang dilakukan pada pekerja emas di India menunjukkan bahwa lama kerja sedikit lebih lama dari normalnya dimana durasi kerja per hari rata-rata 12 jam $(\mathrm{SD}=2,11)$, durasi istirahat rata-rata per hari 1 jam $(\mathrm{SD}=1,00)$, dan jumlah hari kerja dalam seminggu rata-rata 6 hari. Hal ini dapat memberikan pengaruh pekerja akan merasa lebih cepat kelelahan. ${ }^{15}$

Status gizi pekerja tergantung dari asupan gizi yang masuk untuk memenuhi kebutuhannya, jika antara asupan dan kebutuhan tubuh itu seimbang maka status gizi akan normal atau baik. Penentuan status gizi pada penelitian ini melibatkan para pengrajin emas. Indeks Massa Tubuh (IMT) digunakan untuk menilai status gizi pengrajin emas. Pengukuran status gizi menggunakan berat bandan dan tinggi badan, dengan kategori kurus $\left(<18,5 \mathrm{~kg} / \mathrm{m}^{2}\right)$, normal $\left(18,5-24,9 \mathrm{~kg} / \mathrm{m}^{2}\right)$, gemuk $\left(>25-29,9 \mathrm{~kg} / \mathrm{m}^{2}\right)$ serta obesitas $\left(>30 \mathrm{~kg} / \mathrm{m}^{2}\right)$.

Berdasarkan hasil penelitian bahwa status gizi tertinggi dengan persentase $70 \%$ kategori normal, persentase gemuk 20,0\% dan persentase kurus $10,0 \%$. Sedangkan rata-rata diperoleh 2,10 dan standar deviasi 0,548. Berdasarkan data status gizi pekerja bahwa asupan makanan sebagai sumber tenaga berperan penting dalam memenuhi kebutuhan energi, karena sesuai atau sepadan dengan berat kerjaan pengrajin emas.

Berdasarkan rata-rata status gizi dengan tingkat kelelahan kerja rendah-sedang tinggi masing-masing adalah 18,50; 15,58; 12,25. Berdasarkan nilai $p$-value $=0,311 \quad$ sehingga menunjukkan tidak hubungan status gizi dengan kelelahan kerja dengan nilai $p$-value $=0,311$. Artinya gizi yang baik merupakan faktor penentu dalam menentukan kesehatan dan produktivitas kerja. Hal ini dapat dipengaruhi oleh status gizi responden rata-rata dalam keadaan normal yaitu $70 \%$.

Sejalan dengan penelitian yang dilakukan PT. Sari Usaha Mandiri Bitung menunjukkan bahwa tidak ada hubungan yang bermakna antara status gizi dengan kelelahan kerja $(p$-value $=0,069) .{ }^{16}$ Penelitian yang dilakukan pada pekerja PT. X Batang juga menunjukkan tidak terdapat hubungan status gizi dengan kelelahan kerja dengan nilai $p$ - 
value $=0,129 .{ }^{17}$ Penelitian lain yang dilakukan di bagian penjahitan di CV. Aneka Garment Gunungpati dan di PT. Antam Tbk. UBPP Logam Mulia menemukan bahwa tidak terdapat hubungan status gizi dengan kelelahan kerja ( $p$-value $=0,191$ dan $p$-value $=0,224) .{ }^{18} 19$

Meskipun hasil penelitian menunjukkan tidak terdapat hubungan status gizi dengan kelelahan kerja pada pengrajin emas, hal ini tetap akan mempengaruhi produktivitas pekerja dalam bekerja. Pekerja dengan status gizi kurang, akan cenderung untuk mengalami kelelahan kerja akibat asupan gizi kurang untuk memenuhi kebutuhan pekerja dalam menghasilkan energi, selain itu pekerja akan merasa cepat mengantuk dan kurang konsentrasi dalam bekerja, demikian juga pekerja yang berstatus gizi lebih dapat mengakibatkan pergerakan menjadi terhambat sehingga berpengaruh pada produktivitas kerja. ${ }^{20}$.

\section{KESIMPULAN DAN SARAN}

Ada hubungan antara lama kerja dengan kelelahan kerja pada pengrajin emas di Kelurahan Malimongan Kota Makassar dan tidak ada hubungan antara status gizi dengan kelelahan kerja pada pengrajin emas di Kelurahan Malimongan Kota Makassar. Diharapkan kepada pihak terkait melakukan sosialisasi tentang kelelahan kerja dan pencegahannya khususnya kepada para pengrajin emas untuk membatasi jam kerja serta istirahat yang cukup dan tepat waktu dan melakukan peregangan pada saat bekerja, serta pengrajin emas dapat mempertahankan status gizi dengan meningatkan konsumsi makanan yang bergizi agar mendapatkan status gizi yang normal. Perlu dilakukan penelitian terkait dengan faktor lain yang mempengaruhi kelelahan kerja pada pengrajin emas dengan memperhatikan faktor psikologis pekerja dan kondisi tempat kerja.

\section{UCAPAN TERIMA KASIH}

Terima kasih kepada Ketua Yayasan Mitra Karya Persada dan Direktur Politeknik Karya Persada Muna yang telah mendukung pelaksanaan penelitian ini, Pemerintah Kota Makassar dan Lurah Malimongan yang telah memberikan izin pelaksanaan penelitian, serta teman profesional dosen yang telah membantu menyusun artikel ini.

\section{DAFTAR PUSTAKA}

1. Susanti S, Amelia AR. Faktor Yang Berhubungan Dengan Kelelahan Kerja Pada Pekerja PT Maruki International Indonesia Makassar Tahun 2018. In: Prosiding Seminar Nasional Sinergitas Multidisiplin Ilmu Pengetahuan dan Teknologi. 2019. p. 231-7.

2. Mustofani M. Hubungan Faktor Internal Dengan Kelelahan Subjektif Pekerja. Med Technol Public Heal J. 2020;4(1):61-9.

3. Suma'mur S. Kesehatan Kerja dalam Perspektif Hiperkes dan keselamatan Kerja. Jakarta: Erlangga; 2014.

4. Ekawati LP. Pengaruh Profesionalisme, Pengalaman Kerja dan Tingkat Pendidikan Auditor, Terhadap Pertimbangan Tingkat Materialitas (Studi Empiris Pada Kantor Akuntan Publik di Wilayah Bali). J Ilm Akunt dan Humanika. 2013;3(1).

5. Tarwaka. Ergonomi Industri Dasar-dasar pengetahuan ergonomi dan aplikasi di tempat kerja. Surakarta: Harapan Press; 2014. 
6. Savety P. Fatigue Risk Manajemen Assesment and Plant, Predictivesavety. 2020.

7. Setyawati L. Selintas tentang kelelahan kerja. Yogyakarta: Amara Books. 2010;28-33.

8. Langgar DP, Setyawati VAV. Hubungan Antara Asupan Gizi Dan Status Gizi Dengan Kelelahan Kerja Pada Karyawan Perusahaan Tahu Baxo Bu Pudji Di Ungaran Tahun 2014. VISIKES J Kesehat Masy. 2014;13(2).

9. Salasa N, Kolibu F, Punuh M. Hubungan Antara Umur, Masa Kerja Dan Status Gizi Dengan Kelelahan Kerja Pada Pekerja Di Bagian Loining PT. Sinar Pure Foods Internasional Bitung. 2017 [Internet]. Available from: http://www.ejournalhealth.com/index.php/\%0 Amedkes/article/download/364/355.

10. Sari AR, Muniroh L. Hubungan Kecukupan Asupan Energi dan Status Gizi dengan Tingkat Kelelahan Kerja Pekerja Bagian Produksi (Studi di PT. Multi Aneka Pangan Nusantara Surabaya). Amerta Nutr. 2017;1(4):275-81.

11. Sugiyono. Statistika Untuk Penelitian. Bandung: Alfabeta; 2014.

12. Notoatmodjo S. Metodologi penelitian kesehatan. Jakarta: Rineka Cipta; 2012.

13. Ganguly S, Guray A. Socio-economic Profile of Gold Mongers and Goldsmiths-A Case Study of Sonapatti Area in Barddhaman Town of West Bengal. Vol. 2, International Journal of Humanities \& Social Science Studies (IJHSSS). Published by Scholar Publications Karimganj, Assam, India; 2015. p. $305-15$.
14. Datu MMD, Kawatu PAT, Mandagi CKF. Hubungan Antara Lama Kerja Dengan Kelelahan Kerja Pada Pengendara Ojek Online Komunitas Manguni Rider Online Sario. KESMAS. 2019;8(6).

15. Ghosh T, Das B, Gangopadhyay S. Workrelated musculoskeletal disorder: an occupational disorder of the goldsmiths in India. Indian $\mathrm{J}$ community Med Off Publ Indian Assoc Prev Soc Med. 2010;35(2):321.

16. Malonda AA, Kawatu PAT, Malonda NSH. Hubungan Antara Umur, Waktu Kerja Dan Status Gizi Dengan Kelelahan Kerja Pada Tenaga Kerja di Bagian Produksi PT. Sari Usaha Mandiri Bitung. Fakultas Kesehatan Masyarakat, Universitas Sam Ratulangi Manado, http://fkm ...; 2015.

17. Lestantyo MS, Triyunita N. Hubungan Beban Kerja Fisik, Kebisingan dan Faktor Individu dengan Kelelahan Pekerja Bagian Weaving PT. X Batang. J Kesehat Masy Univ Diponegoro. 2013;2(2):18742.

18. Wahyuni D, Indriyani I. Faktor-faktor yang Berhubungan dengan Kelelahan Kerja pada Pekerja Bagian Produksi di PT. Antam Tbk. UBPP Logam Mulia. J Ilm Kesehat. 2019;11(1):73-9.

19. Atiqoh J, Wahyuni I, Lestantyo D. FaktorFaktor yang berhubungan dengan kelelahan kerja pada pekerja konveksi bagian penjahitan di CV. Aneka Garment Gunungpati Semarang. J Kesehat Masy. 2014;2(2):119-26.

20. Melati S. Hubungan Antara Umur, Masa Kerja Dan Status Gizi Dengan Kelelahan 
Kerja Pada Pekerja Mebel Di Cv. Mercusuar

Dan Cv. Mariska Desa Leilem Kecamatan

Sonder Kabupaten Minahasa. Universitas

Sam Ratulangi; 2013. 